\title{
Linear Programming Model for the Measurement of Environmental Performance in Wine Industry-Concepts and Empirical Results
}

\author{
Shiang Chen and Jung-Hua Wu \\ Department of Resources Engineering, National Cheng Kung University, 70145 Tainan City, Taiwan
}

\begin{abstract}
In Taiwan we are currently facing serious air pollution problems, PM2.5 airborne particles not only endanger the human body, leading to coughing, asthma, chronic bronchial and other respiratory diseases, but it is also carcinogenic, our basic rights for survival has been seriously threatened. According to the latest study by the Environmental Protection Agency, the industrial sector accounts for about $25 \%$ of the sources of air pollution in Taiwan. The winemaking industry, with raw materials has several stages of production; it must use electricity, water, oil, diesel, gasoline, and steam as energy. The final product is not only wine, but also the discharge wastewater, lees, $\mathrm{CO}_{2}$, waste gas, etc. Different process methods will produce different energy consumption results, thus providing the possibility of $\mathrm{CO}_{2}$ reduction. This study takes the winemaking industry as a case study, trying to find out how to achieve a concept of "win-win situation "for both sides of carbon reduction and economy development. First, aiming at the policy of energy saving and carbon-reduction inventory of winery, trying to find out the source of pollution and the change of pollution source during 2008-2016, and then according to the data, the empirical results are analysed. Finally, a linear programming model proposed for the production planning of winemaking processes to achieve maximum operational profit while reducing $\mathrm{CO}_{2}$ emissions. The options considered in this research are levy the carbon tax in different prices to decrease $\mathrm{CO}_{2}$ emissions; installation of new equipment to enhance capacity; switching production schedule that emits less $\mathrm{CO}_{2}$. The objective of the linear programming model is to determine suitable $\mathrm{CO}_{2}$ mitigation options for a given reduction target while meeting the demand of each final product, quality specifications, and simultaneously maximizing profit. In this research, How to achieve the optimal production goals: minimizing the cost \& energy consumption, and the maximum production value become the optimal production objection.
\end{abstract}

\section{Introduction}

In Taiwan, trading market of $\mathrm{CO}_{2}$ emission is small, the effect of carbon tax maybe better than emissions trading. Therefore, we use linear programming, carbon tax, and inventory of energy saving to explore optimal production in the winemaking industry. This paper presents linear programming for the optimal production, it based on the input-output activity to assess the potential impacts of energy consumption, $\mathrm{CO}_{2}$ emission and seek a production schedule that will increase the profit of winemaking industry [1]. There are seven kinds of product for research object; red label rice cooking wine (code a1); red label pure rice cooking wine (code a2); super red label rice wine (code a3); super red label pure rice wine (code a4); super red label pure rice wine (code a5); red label rice wine water (code a6); wine gift box (code a7). Data are analysed by MATLAB simulation software, and use CVX module to solve problems. This optimization model used to estimate the potential $\mathrm{CO}_{2}$ emissions mitigation strategies by minimizing the $\mathrm{CO}_{2}$ emissions under the different prices of carbon tax. Several mitigation strategies have applied to analyse the effect of $\mathrm{CO}_{2}$ emissions reduction. In this paper, first, we describe the data source and methodology, then the linear programming model of the winemaking industry established, aiming at the goal of minimizing costs and maximizing profits, we discuss the influence of changes to energy consumption and the decrease of $\mathrm{CO}_{2}$ due to the levy of carbon tax [2]. Finally, a case study of greenhouse gas inventory for energy saving and carbon reduction in winery are analysed. We analyse and compare the sources of greenhouse gas emissions in the winery during 2008-2016.

\section{Data source and methodology}

Carbon reduction projects in Taiwan has been in operation for many years, according to the figure 1, the latest carbon emissions results released in 2017, the overall carbon emission is the highest in nearly a decade. Our greenhouse gas reduction targets are to achieve greenhouse gas emissions reductions from 2.93 million /ton reduce to 2.82 million/ton in 2020. This paper attempts to option the effective policy that can assist Taiwan to reduce the $\mathrm{CO}_{2}$ emissions. All the data are provided by winery, it's an actual operating condition in 2017, and an optimization model" linear programming model" is to estimate the potential $\mathrm{CO}_{2}$ emissions mitigation strategies for winemaking industry by minimizing the $\mathrm{CO}_{2}$ emissions under the constraint of different prices of carbon tax [3]. 


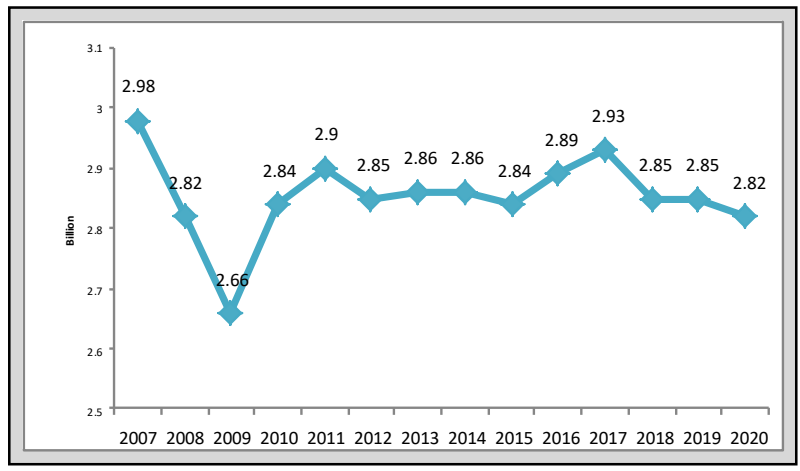

Figure 1. $\mathrm{CO}_{2}$ Emission Trends Overall Taiwan.

Source: http://teds.epa.gov.tw

\subsection{Definition of variables}

\subsubsection{Formatting the title}

$a_{i j}$ :The input of $\mathrm{i}$ process to the $\mathrm{j}$ item process, and the decision variable for the research model

$C_{j p}$ : Cost refers to the wine system on the $\mathrm{j}$ process

$p_{j}$ : Price factor of $\mathrm{j}$ product

$\overline{\mathrm{CO}_{2}}$ : Upper constrains of the total $\mathrm{CO}_{2}$ emission.

$e_{q j}$ : The $\mathrm{j}$ production process, the need for q-type energy unit input

Pc: It indicates the $\mathrm{CO}_{2}$ tax rate

$u_{q}$ : $\mathrm{CO}_{2}$ emissions caused by the use of the $\mathrm{q}$ energy

$$
\begin{array}{cc}
\underset{a_{i} \ldots a_{M}}{\operatorname{maximize}} & \sum_{i=1}^{M} P_{i} a_{i}-\sum_{i=1}^{M} C_{i} a_{i}-\sum_{i=1}^{M} E_{i} a_{i}-P_{c} \sum_{i=1}^{M} Q_{i} a_{i} \\
\text { subject to } & a_{i}>=0, i=1, \ldots, M \\
& \sum_{i=1}^{M} a_{i} \leq C A P \\
& a_{i} \leq \bar{a}_{i} \quad i=1, \ldots, M . \\
& \sum_{i=1}^{M} Q_{i} a_{i} \leq \mathrm{CO} O_{2}
\end{array}
$$

Where $\mathrm{M}$ is 7, i.e, 7 products

$a_{i}$ Means the quantity of product produced in one month.

$P_{i}$ Means the price of product

$c_{i}$ Means the cost of product

$E_{i}$ Means the energy consumption (water, fuel, and electricity)

of product

$P_{c}$ Means the carbon tax

$Q_{i}$ Means the $\mathrm{CO}_{2}$ emission of product

CAP Means total quantity limitation

$\bar{a}_{i}$ Means the limitation quantity of product

co2 Means limitation of $\mathrm{CO}_{2}$ emission

eq(1) means each quantity of product should be positive.

eq(2) means total quantity should less than total quantity limitation.

eq(3) means the quantity of product should not larger than the limitation of it. eq(4) means the emission should not larger than limitation of $\mathrm{CO}_{2}$ emission.

\section{Case study of winery}

In Taiwan, our greenhouse gas reduction targets are to achieve greenhouse gas emissions reductions for 2025, and to encourage energy-intensive industries to use the best energy efficient technology to effectively manage energy and improve efficiency, especially in industries that must seek the most efficient usage of energy, that is, the minimum $\mathrm{CO}_{2}$ emissions operation, to pursuit profit maximization. According to Figure 2, the energy consumption in the industrial sector is the largest, in 2016, for example, the energy consumption of the industrial sector accounts for about one-third (37.2\%) of the total consumption of energy. Overall, the industrial sector is the most important energy consumer, and the main source of $\mathrm{CO}_{2}$ emission [4].

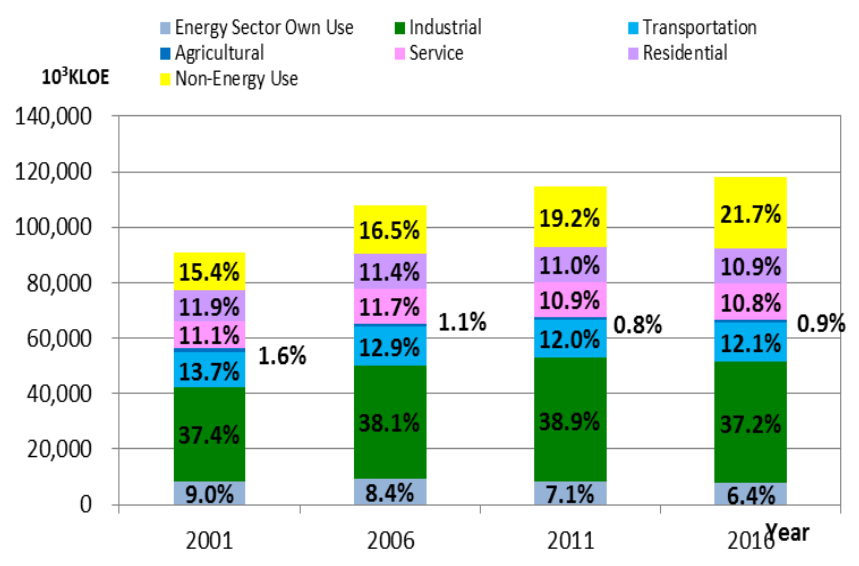

Figure 2. Taiwan's Energy Supply Structure (Sector).

Bureau of Energy (2016)

Refer to the Figure 3, the winemaking industry, with rice, millet, barley, or sorghum as raw materials, has several stages of production process, such as soaking, cooking, cooling, fermentation, distillation, storage, blending, filtration, bottling, packaging, and transportation. During the process distilleries must use electricity, water, oil, diesel, gasoline, and steam as energy. The final product is not only wine, but also the discharge wastewater, lees, $\mathrm{CO}_{2}$, waste gas, etc. Different process methods will produce different energy consumption results, thus providing the possibility of $\mathrm{CO}_{2}$ reduction. As the winemaking industry maximizes the pursuit of profits, so in this study, first we must establish the linear programming model of the winemaking industry, then under the goal of profit maximization, we explore the carbon tax and the interrelationship caused by changes in energy consumption and the impact of $\mathrm{CO}_{2}$ reduction, finally we analyze the $\mathrm{CO}_{2}$ inventory policy of the winery during a period from 2008 to 2016. 


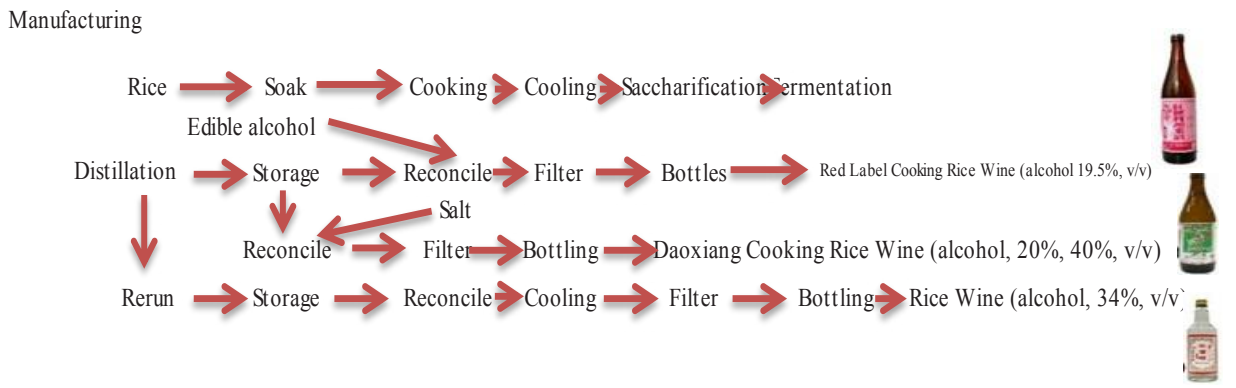

Figure 3. Process of wine making.

source: designed by the author

\subsection{The policy of greenhouse gas inventory in winery}

The organization of greenhouse gas emissions inventory established on January 6, 2005 and divided into many departments. The classification and definition of emission sources according to ISO/CNS 14064-1 and GHG Protocol are as follows:

Category 1: Direct greenhouse gas emissions mainly caused by routine operating activities.

Category2: Indirect greenhouse gas emissions (electricity).

Category 3: The other indirect greenhouse gas emissions.

\subsection{Greenhouse gas emission sources in winery 2008-2016}

With the policy of energy saving and carbon reduction measures, winery actively committed to the greenhouse gas inventory from 2010, they held regular meetings, scheduled time and audit date since 2012. Analysis of the types of greenhouse gas emissions from 2008 to 2016, as shown in Figure 4, the source of fixed fuel oil as the main source, followed by wastewater, process emissions, electricity and outsourcing. Figure 4 shows that fuel oil, electricity, outsourcing and fixed diesel $\mathrm{CO}_{2}$ Emissions reduced significantly, especially in the other escape emission and acetylene reduction, but the wastewater, refrigerant escape and septic tank $\mathrm{CO}_{2}$ emissions increased a bit.

Unit: metric ton $\mathrm{Co}_{2} /$ year

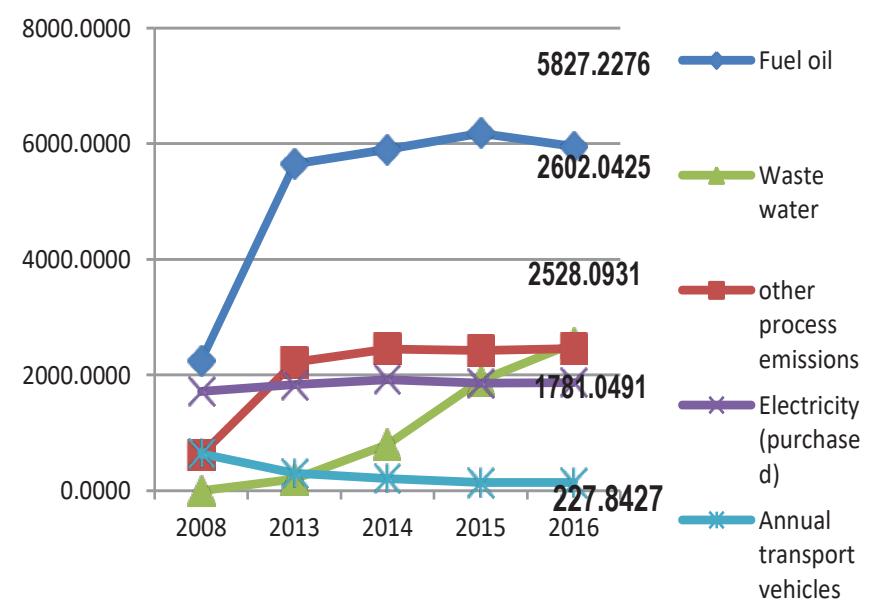

Figure 4. Greenhouse Gas Emission Sources 2008- 2016

\subsection{Comparison of emissions source during the period 2015-2016}

From Figure 5 comparisons of emissions 2015-2016. Fuel oil decrease from $49 \%$ to $45 \%$, the process emissions decrease from $20 \%$ to $19 \%$, electricity maintains $14 \%$, wastewater increase from $14 \%$ to $20 \%$. Wastewater discharge is still a problem, due to mainly increase in production; winery must to help the distiller's grains sales and removal to solve the problem. 
Comparison of emissions source 2015
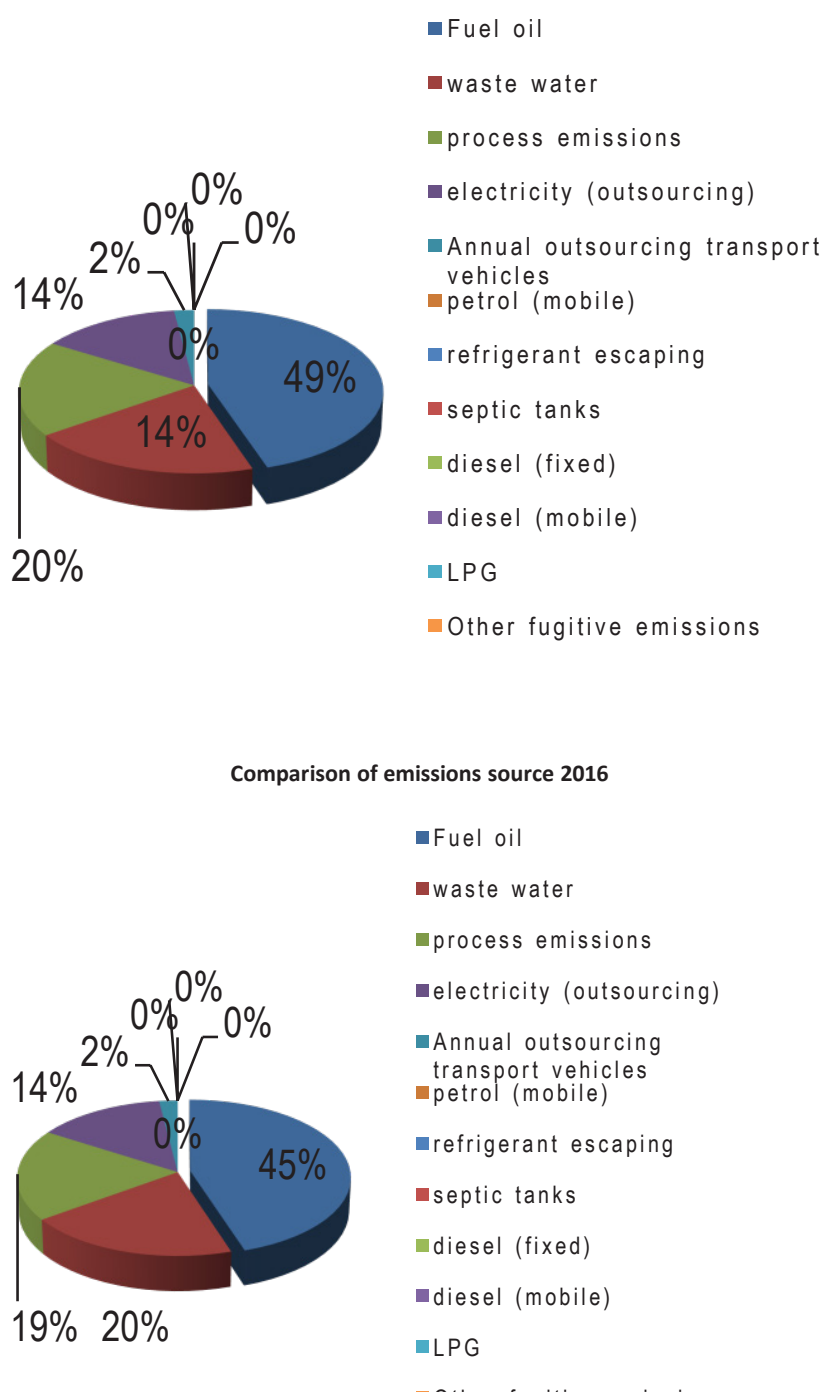

Figure 5. Emissions Source of 2015-2016.

Source: Author draws on data

\subsection{Comparison of energy intensity.2005-2016}

Energy intensity is an international indicator of the overall energy efficiency of a country. It represents the production process, the output of each unit of domestic gross domestic product (GDP) need to consume energy, calculated by the total energy consumption, it divided by gross domestic product.

Energy Intensity = Energy Consumption / GDP

If a country has a high energy intensity, it means that the cost of energy conversion to GDP is high; if the energy intensity decline will show that the creation of a unit of gross domestic production, the amount of resources usage is declining, the efficiency energy usage has improved, the situations of environment damage is also reduced. From Figure 6 Intensity Ratio, It shows that product intensity, service intensity and turnover intensity in the period 20052016 are trend of decreasing and flat for a long-term.

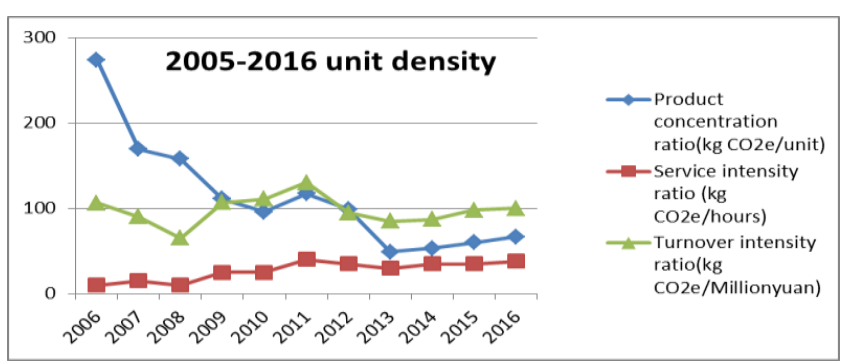

Figure 6. Comparisons of Energy Intensity 2005-2016.

Source: Author draws based on data.

\section{Linear programming model for the measurement of environmental performance}

In this research, first we establish linear programming model then set carbon tax prices, by $\mathrm{CO}_{2}$ tax mechanism to analyse changes in the production scheduling process and energy usage, finally under the goal of maximizing profit, to explore the interaction between changes in production scheduling and $\mathrm{CO}_{2}$ emissions reductions.

\subsection{The goal of the linear programming model}

The goal of the linear planning model of wine industry is the combination of output interest, input cost and carbon cost, expression in monetary terms; the energy goal is to minimize energy input, in terms of quantity or currency; the environmental goal is to minimize $\mathrm{CO}_{2}$ emissions by quantity. According to the Figure 7, there are three targets of the linear planning model. They are economy, energy and environmental protection [5]. Since the purpose is to produce in the production process of obtaining the maximum profit, however, profit is the value of the product portfolio produced in the production process and the cost invested in the manufacturing process, therefore in this study; we must consider minimizing $\mathrm{CO}_{2}$ emissions the amount of environmental objectives. The following chart shows the concept of wine industry; its targets are as follows [6]:

1. Economic target:

Optimize the allocation of resources, the pursuit of the maximization of production value. The mathematical formula be measured in monetary units

$$
\operatorname{Max} \sum_{j=m+1}^{n} \sum_{i=1}^{m} p_{j a_{i j-}} \sum_{j=1}^{m} \sum_{i=1}^{m} c_{j p a i j}
$$

2. Energy Target:

Fixed capital investment, the pursuit of the minimum energy supply

Energy goal: $\sum_{j=1}^{m} \sum_{i=1}^{m} p_{c Q_{j}} a_{i j}$

3. Environmental target:

The pursuit of optimal profit conditions, $\mathrm{CO}_{2}$ emissions are minimized

Environmental goal: $\operatorname{Min} \sum_{j=1}^{m} \quad \sum_{i=1}^{m}$ Qjaij 


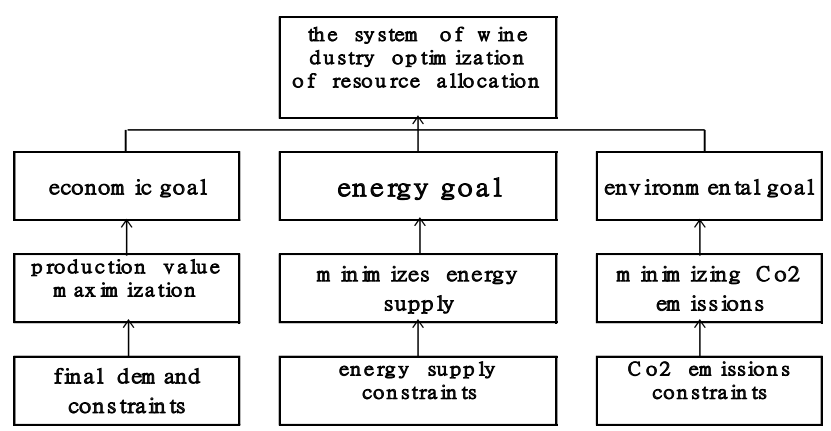

Figure 7. The Goals of Linear Programming. Source: Author draws based on data

\subsection{Application of linear programming model}

The purpose of this study is to explore the impact of the levy of carbon taxes on $\mathrm{CO}_{2}$, emissions and to pursue environmental goals with minimal $\mathrm{CO}_{2}$, emissions. First, we give a tax level to explore the impact of the levy of carbon tax, then multiply the emissions by the tax rate and convert it into currency units. The environmental goal is mainly that when the carbon tax occurs $\mathrm{CO}_{2}$ emissions can achieve a minimum goal [7] so this study sets the minimum environmental cost in the target equation. It is as follows:

$$
\operatorname{Min} \sum_{j=1}^{m} \quad \sum_{i=1}^{m} Q j a i j
$$

At different levels of carbon tax, the changes in production schedules within each process of the winemaking framework, the changes in energy consumption and the impact on $\mathrm{CO}_{2}$ reductions both discussed. To maximize the value of production under the goal of minimizing the use of energy demand and minimizing $\mathrm{CO}_{2}$ emissions.

\subsection{Empirical simulation results}

The application of linear programming model, first we embody the model, and then use Mat lab software to simulate the changes in the production schedule, which based on the level of carbon tax and under the basic situation of minimizing energy usage. Refer to the Table 1, the results show that the production benefit is (6731809) U.S. dollars per month, the total energy consumption is (12342.45) Kcal/month, and the total $\mathrm{CO}_{2}$ emission is (1743.714) metric ton/month. At this time, $\mathrm{CO}_{2}$ has not set price, it regard as the total emission limitation, so in this study we use this total $\mathrm{CO}_{2}$ emission as the $\mathrm{CO}_{2}$ emission constrain.

Table 1. Empirical simulation results under different carbon taxes.

\begin{tabular}{|c|c|c|c|c|c|c|c|}
\hline $\begin{array}{c}\text { CO2 } \\
\text { price }\end{array}$ & 0 & 90 & 120 & 150 & 180 & 210 & 230 \\
\hline CO2 & mt & /month \\
\hline $\begin{array}{c}\text { Total } \\
\text { emission }\end{array}$ & 52311.42 & 26824.93 & 26824.91 & 23845.76 & 23845.76 & 18082.02 & 17714.83 \\
\hline fuel & 12342.45 & 12342.48 & 12342.48 & 12331.86 & 12331.86 & 2331.86 & 12331.86 \\
\hline electricity & 83.87539 & 83.86877 & 83.86877 & 83.82213 & 83.82213 & 83.80743 & 83.81134 \\
\hline steam & 12248.64 & 12247.71 & 12247.71 & 12241.07 & 12241.07 & 12239.59 & 12240.17 \\
\hline cost & US\$ & /month & \multicolumn{7}{|c|}{} \\
\hline Total & 3516391 & 3150450 & 3686948 & 4302405 & 5017778 & 4797977 & 5288715 \\
\hline Fix cost & 1982900 & 1854641 & 1854641 & 1765104 & 1765104 & 1569835 & 1573156 \\
\hline $\begin{array}{c}\text { Variable } \\
\text { cost }\end{array}$ & 1533491 & 1027559 & 1027559 & 1106556 & 1106556 & 1058300 & 1058335 \\
\hline COO cost & 0 & 268249.3 & 804747.4 & 1430746 & 2146119 & 2169842 & 2657225 \\
\hline value & 6731809 & 5850126 & 5850125 & 5696954 & 5696954 & 4898471 & 4857764 \\
\hline
\end{tabular}

According to the Figure 8, different carbon tax prices have different ways of distributing production capacity: When carbon taxes levels are low, wine producers will continue to produce high-energy but with a high profits product.

According to figure 9 while the carbon tax is higher, the industry will not produce products with high carbon emissions; instead, they will choose products with lower net profit, but lower energy consumption.

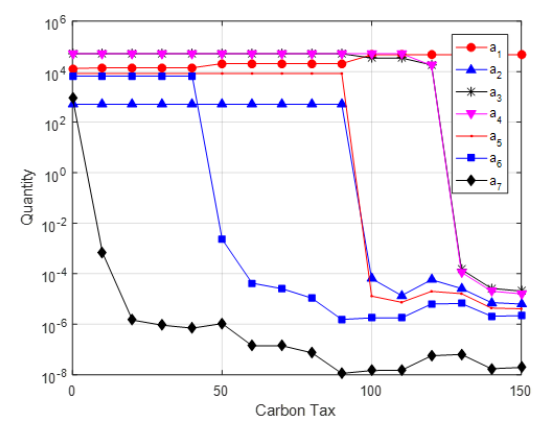

Unit: us\$/Mt

Figure 8. The Interaction between Carbon Tax and the Quantity. 


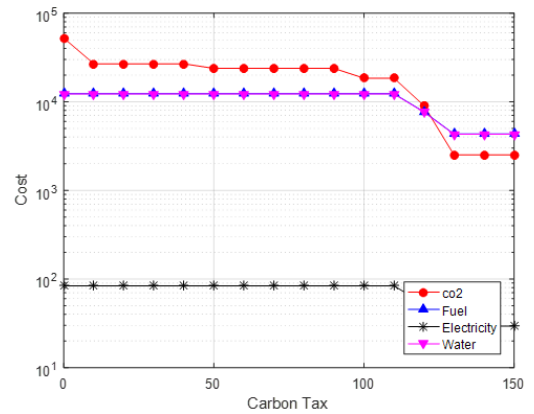

Unit: us\$/Mt

\subsubsection{Cost changes at different carbon tax levels}

After the levy of the carbon tax, the winemaking producer will reduce the fixed cost and operating cost through reducing the use of fuel and adjusting the operating cost to

reduce the cost of $\mathrm{CO}_{2}$ emissions. Refer to the Table 2 owing to the tax costs of $\mathrm{CO}_{2}$ emissions, the total cost will increase. However, as the carbon tax level increases, the ratio of fixed costs and operating costs to total costs will decrease slightly.

Figure 9. The Interaction between Carbon Tax and the Cost of Energy.

Table 2. Cost changes at different carbon tax levels.

\begin{tabular}{|c|c|c|c|c|c|c|c|}
\hline $\mathbf{C O}_{\mathbf{2}}$ & 0 & 90 & 120 & 150 & 180 & 210 & 230 \\
\hline Total cost & 3516391 & 3150450 & 3686948 & 4302405 & 5017778 & 4797977 & 5288715 \\
\hline $\begin{array}{c}\text { Fixed } \\
\text { and } \\
\text { operating } \\
\text { costs }\end{array}$ & 3516391 & 2882201 & 2882200 & 2871660 & 2871660 & 2628135 & 2631490 \\
\hline$\%$ & 100 & 91.48537 & 78.17307 & 66.74544 & 57.2297 & 54.7759 & 49.75671 \\
\hline Tax costs & 0 & 268249.3 & 804747.4 & 1430746 & 2146119 & 2169842 & 2657225 \\
\hline$\%$ & 0 & 8.514633 & 21.82693 & 33.25456 & 42.7703 & 45.2241 & 50.24329 \\
\hline
\end{tabular}

\subsubsection{Tax effect analysis}

In terms of the concept of cost-effectiveness, the best carbon tax effect can obtain when the cost of $\mathrm{CO}_{2}$ emission reduction is equal to the cost of carbon tax. At this point, the cost of investing in $\mathrm{CO}_{2}$ to reduce emissions will be equal to the taxable cost of the $\mathrm{CO}_{2}$ being collected [8]. In other word, the relative $\mathrm{CO}_{2}$ emission at this time is the optimal production level. According to Table 3 when the cost of reducing $\mathrm{CO}_{2}$ emissions is lower than the cost of tax, the winemaking producer will try its best to reduce $\mathrm{CO}_{2}$ emissions. However, when the cost of reducing $\mathrm{CO}_{2}$ emissions is higher than the cost of tax, winemaking producer will adopt a strategy of preferring to pay carbon tax to save costs. That is to say, after the $\mathrm{CO}_{2}$ tax, whether the producer will substantially reduce its carbon emissions will determine whether the taxable cost of $\mathrm{CO}_{2}$ has already exceeded the $\mathrm{CO}_{2}$ emission reduction costs. When $\mathrm{CO}_{2}$ 's taxable costs are lower, it is less likely to commit to carbon reduction because carbon tax is beneficial to the industry. In other words, after the $\mathrm{CO}_{2}$ tax, whether the wine industry will actually reduce $\mathrm{CO}_{2}$ emissions decide whether the tax cost of $\mathrm{CO}_{2}$ has already exceeded the $\mathrm{CO}_{2}$ emission reduction cost. When the $\mathrm{CO}_{2}$ tax cost is low, because the payment of carbon tax is beneficial to the industry, it is less likely to commit itself to commit carbon reduction [9].

Table 3. Tax effects under different carbon taxes.

\begin{tabular}{|c|c|c|c|c|c|c|}
\hline $\begin{array}{c}\text { CO2 price } \\
\text { US/Mt }\end{array}$ & 90 & 120 & 150 & 180 & 210 & 230 \\
\hline CO2 reduction \\
\hline Mt/month & 25486.49 & 25486.5 & 28465.65 & 28465.65 & 34229.4 & 4596.59 \\
\hline $\begin{array}{c}\text { \% } \\
\text { Mt }\end{array}$ & 48.90861 & 48.90862 & 55.98457 & 55.98457 & 72.29255 & 72.99447 \\
\hline $\begin{array}{c}\text { Cost of Profit } \\
\text { and loss point } \\
\text { US/Mt }\end{array}$ & 39251.27 & 39251.26 & 36261.44 & 36261.44 & 30497.68 & 30130.5 \\
\hline CO2 Tax effect \\
\hline \begin{tabular}{c} 
US/Mt \\
\hline $\begin{array}{c}\text { The proportion } \\
\text { of carbon tax\% }\end{array}$
\end{tabular} 626824.93 & 26824.91 & 23845.76 & 23845.76 & 18082.02 & 17714.83 \\
\hline
\end{tabular}




\section{Conclusion}

In this research, we make use of linear programing model to explore complicated winemaking process architecture and compare changes in $\mathrm{CO}_{2}$ emissions before and after the carbon tax levied. The process of simulation is first to simulate the situation of carbon tax which has not been levied as a basic situation, and to calculate the total emission of $\mathrm{CO}_{2}$ under the basic situation simulation as the discharge constrain, then to observe the interaction between the carbon tax level and production capacity. Due to our goals are to minimize the demand for energy usage; to minimize $\mathrm{CO}_{2}$ emission, and pursuit the maximizing production value.

According to the tax effect analysis, the result shows that: 1. Different carbon tax level has different ways of distributing production capacity.

2. When carbon tax levels are lower, wine producers will continue to produce high energy but with a high profits product.

3. While the carbon tax is higher, the industry will not produce products with high carbon emissions. Instead, they will choose products with lower net profit, but lower energy consumption, in other words the wine industry will undergo to change production schedules that will change the usage of energy and thus reduce the total $\mathrm{CO}_{2}$ emissions. Especially the huge enterprises only high level of carbon tax can force them to reduce the $\mathrm{CO}_{2}$ emission.

4. After carbon tax levy, wine industry is under pressure to reduce their tax costs and thus change their production schedules, and by changing production schedules, they have changed the structure of their energy usage towards lowercarbon production, and the higher the levy of carbon tax, the greater the effect of carbon reduction.

5. However, when the carbon tax is too high, the high cost of tax barriers will occur and the output need to meet with the final demand of each product, the carbon reduction effect is limited. In terms of cost, the levy of carbon tax can trigger the effect of $\mathrm{CO}_{2}$ reduction.

6. When the carbon reduction cost is equal to the taxable cost, the carbon tax effect of $\mathrm{CO}_{2}$ reduction will result. The profit and loss balance point is the best carbon tax level. If the carbon tax level is greater than the best tax rate at the Profit \& Loss balance, there is an incentive force the industry to make a mandatory reduction. After levying carbon tax, the results show that when the cost of tax is more than the cost of reducing $\mathrm{CO}_{2}$ emissions, wine industry will change the strategy to achieve $\mathrm{CO}_{2}$ emission reduction, and get the tax effect.

This result also shows that the main source of the $\mathrm{CO}_{2}$ emissions is fuel oil, followed by wastewater, process emissions and electricity. The $\mathrm{CO}_{2}$ emissions improved significantly during the period of 2008 - 2016, the fuel oil, electricity, diesel, outsourcing and other emission had total decreased by $1.78 \%$. The methods of the $\mathrm{CO}_{2}$ reduction are:

1. Technical adjustments, such as packaging time in the off-season which is set from June to September, Centralizing manufacturing, reducing the times of boiler boot, blocking unnecessary pipelines, maintaining the steam pipe insulation facilities and strengthening the energy conservation advocacy. The most important thing is renewing the equipment.

2. This research also shows the intensity ratio indicator, in product density, service intensity and turnover intensity during the 2008-2016, there were a lower and flatter trend.

\section{References}

1. D. Babusiaux, A. Pierru, Appl. Energy. 84, 828 (2007).

2. J.E. Aldy JE, Ley E, Parry IWH, Natl. Tax. J 61, 493 (2008).

3. A.T.N. Moghaddam, C. Michelot, Eur. J. Oper. Res 197, 999 (2009).

4. C.F. Lee, S. J. Lin, C. Lewis, Energy. Policy 36, 722 (2008).

5. S. Soleille, Energ. Policy 34, 1473 (2006).

6. S. Soimakallio, L. Saikku, Energy 38, 3 (2012).

7. M.S. Chang, Clean Technol Envir 16, 1001 (2014).

8. A. Omu, R. Choudhary, A. Boies, Energy. Policy 61, 249 (2013).

9. Z. Wen, F. Meng, M Chen, J. Clean. Prod, 65, 120 (2014). 